\title{
NIH Roadmap for Medical Research
}

National Cancer Institute

\section{Source}

National Cancer Institute. NIH Roadmap for Medical Research. NCI Thesaurus. Code C82632.

A program created to address roadblocks to research and to transform the way biomedical research is conducted by overcoming specific hurdles or filling defined knowledge gaps. These programs span all areas of health and disease research and boundaries of the National Institutes of Health (NIH) Institutes and Centers (ICs). These are programs that might not otherwise be supported by the NIH ICs because of their scope or because they are inherentlly risky. 